\title{
Ciudades latinoamericanas o la dialéctica entre la utopía entusiasta y la urbanización retobada ${ }^{1}$
}

\section{Latin American cities or the dialectics between enthusiastic utopia and retuned urbanization}

\section{Cidades latino-americanas ou a dialética entre utopia entusiasmada e a urbanização indômita}

Dra. Marcela Croce ${ }^{2}$

Recibido: 11/07/2016 - Aceptado: 07/09/2016

\begin{abstract}
Resumen
El propósito de este artículo es retomar el pensamiento sobre la ciudad como sede espacial, disparador de ideas, iniciativa política y social y manifestación cultural, enfatizando aquellas producciones discursivas típicas del fenómeno urbano como la crónica de la metrópolis, el rastreo antropológico que define los estratos culturales que coexisten en la sede urbana y el relato policial que restituye el entramado de vínculos que operan en el perímetro ciudadano. A esta última formulación se añaden las actividades delictivas que aprovechan un conjunto de disposiciones y servicios urbanos como infraestructura, tal como destacó Saskia Sassen.

Con ese objetivo se propone un recorrido por un corpus de textos que se detienen en diversos núcleos urbanos y no se restringen a estudiar sus características geográficas y edilicias sino que las inscriben en el conjunto de cada nación, en la historia de los países que integran América Latina (remarcando la tensión entre ciudad y nación que atraviesa la historia occidental) y asimismo en una serie continental que establece una jerarquía de ciudades. Las antiguas capitales virreinales que son México y Lima aparecen confrontadas a la capital del virreinato menor que es Buenos Aires, y a la sede imperial de Río de Janeiro en este recorrido.
\end{abstract}

1 El texto corresponde a la conferencia dictada en el Centro de Estudios Avanzados de la Universidad de Playa Ancha el 20 de junio de 2016.

2 Argentina. Licenciada, Profesora y Doctora en Letras (UBA-Argentina). Se desempeña como docente de "Problemas de Literatura Latinoamericana" en la Facultad de Filosofía y Letras de la Universidad de Buenos Aires. Contacto: marcela.croce@gmail.com 
Palabras clave: Ciudades latinoamericanas - Historia urbana - Crónica ciudadana - Géneros urbanos - Utopía latinoamericana

\section{Abstract}

This article considers the thinking about cities as space headquarters, an idea nest, a political and social initiative and a cultural manifestation, emphasizing those discursive productions typical of the urban phenomenon, as the chronicle of the metropolis, the anthropological search that define the cultural strata coexisting in urban headquarters and the police story that restores the linking network that operate in the city perimeters. This latter statement is followed by criminal activities that exploit a set of provisions and urban services such as infrastructure, as Saskia Sassen pointed out.

With this objective, we propose a tour through a text corpus that deepen in several urban centers and are not restricted to study their geographical characteristics and buildings, but inscribe them in the set of each nation, in the history of the countries that integrate Latin America (highlighting the tension between city and nation now experienced by Western history) and also in a continental series establishing a hierarchy of cities. The old viceregal capitals, i.e. Mexico and Lima face the minor viceroyalty capital -Buenos Aires-and the imperial headquarters of Rio de Janeiro in this route.

Keywords: Latin American cities - Urban history - Citizen chronicle - Urban genres - Latin American utopia

\section{Resumo:}

O objetivo deste artigo é voltar a pensar a cidade como uma sede espacial, desencadeador de ideias, iniciativa política e social e manifestações culturais, enfatizando aquelas produções discursivas típicas do fenômeno urbano, como a crônica da metrópole, o reconhecimento antropológico que define os estratos culturais que coexistem na sede urbana e no relato policial que restitui o tramado de ligações que operam no perímetro da cidade. Nesta última formulação integram-se as atividades criminosas que se aproveitam de um conjunto de disposições e serviços urbanos como a infraestrutura, assim como destacou Saskia Sassen.

Com este objetivo é proposto percorrer por um corpus de textos que vão parar em diversos núcleos urbanos e não só estarão restritos a estudar suas características geográficas e de construção, mas bem estas se inscrevem no conjunto de cada nação, na história dos países que integram América Latina (destacando a tensão entre a cidade e nação através da história ocidental) e também numa série continental que estabelece uma hierarquia de cidades. As antigas capitais do vice-reinado colonial: México e Lima são confrontados a capital do vice-reino menor que é Buenos Aires, e a sede imperial do Rio de Janeiro nesta turnê.

Palavras-chave: Cidades latino-americanas - História Urbana - Crônica cidadã - Gêneros urbanos - Utopia latino-americana. 


\section{La ciudad y su inflexión latinoamericana}

Las utopías han revestido fundamentalmente la forma de la ciudad, tanto con el carácter esperanzado que adquirieron en el Renacimiento como en la condición nefasta que arrastran desde los ejemplos bíblicos de Sodoma y Gomorra alzándose como contracara de la imagen paradisíaca destinada a Jerusalén. Pero resulta evidente que para indagar la ciudad en tanto sede espacial, disparador de ideas, iniciativa política y social y manifestación cultural no es suficiente recortarse sobre esa figuración idealizada con signo diverso sino acudir a los historiadores urbanos. El decano de ellos, Numa Dionisio Fustel de Coulanges, trazó los rasgos que la ciudad seguiría ostentando hasta la actualidad cuando señaló la fundación conjunta de la polis y la necrópolis, estableciendo a la muerte como primer misterio que, si originariamente era abordado por la religión, en las ciudades modernas integra el espectro de intereses de un género típicamente ciudadano como el policial.

La ciudad fue el asiento primitivo de los dioses, reservando a los apóstatas las opciones simétricas del destierro y la muerte, como se ofrecieron a Sócrates. Eso implicaba una relación estrecha entre la función política de la ciudad y el papel territorial asignado a la urbe; entre la protección de las familias, fratrías, tribus y hogares y la construcción de surcos, puertas y murallas que volvían impenetrable el espacio para los extranjeros. La fundación cívica era un acto religioso liderado por el sacerdote, quien guiaba el arado para trazar el contorno espacial en el que se instalarían las deidades.

Sería ocioso demorarse en este momento a los fines de abordar las ciudades latinoamericanas, no porque carezcan de atributos religiosos sino porque el propósito de esta exposición apunta a las urbes modernas, las que corresponden a la historia independiente del subcontinente, construidas en ocasiones sobre las bases indígenas -es el caso de México con Tenochtitlán-, en otros casos ignorando la sede imperial -es lo que ocurre con la fundación de Lima que deja relegado al Cuzco incaico-, a veces con un propósito meramente expoliador -y el ejemplo de Río de Janeiro elevada a capital para transportar el oro de Minas Gerais a Portugal es sintomático al respecto-, o como 
postrer bastión del avance conquistador en el sur, situación que coloca a Buenos Aires en el rol de Ultima Tule.

La creación de ciudades en Latinoamérica a partir de los avances europeos sobre el territorio corresponde a la etapa de predominio de la burguesía que Henri Pirenne (2011) sitúa en la Edad Media, confiriendo a las urbes una función básicamente comercial y admitiendo que si hasta entonces el mapa de Europa distinguía puntos de concentración económica y poblacional, al final del período tales puntos quedarán enlazados, absorbidos en una red fomentada por el crecimiento del comercio y la correlativa disputa del poder por parte de los mercaderes. Una trama similar se esparce por América a medida que se fundan las capitales hispánicas, aunque el proceso inicialmente acelerado que instaló en veinte años varios núcleos entre México y Santiago de Chile se apaciguó posteriormente, distanciando en décadas y hasta en siglos la inauguración de los nuevos centros urbanos.

En ambos casos se repite un mismo fenómeno: el crecimiento de la urbs como territorio, en lugar de fortalecer los vínculos comunales, lleva a la completa declinación de lo que había sido la ciudadanía romana. Tal tradición se conserva durante la Edad Media en Oriente y da paso al bizantinismo, en tanto queda suspendida en Occidente. $\mathrm{Ni}$ derecho especial ni instituciones propias caracterizan estos espacios fundamentalmente comerciales que, frente a la clausura del Mediterráneo por parte del Islam, se ubican de preferencia en los litorales fluviales y hacen coincidir el depósito de mercancías con el puerto desde donde logran distribuirse. La ciudad resume así la vida nacional, controla la economía de la región y queda certificada como centro expansivo que administra la producción.

La tesis de Pirenne que continúa el hallazgo de Fustel de Coulanges sobre el origen religioso, es que las ciudades medievales fueron asientos episcopales y solamente cuando integraron al sector militar y al comercial se convirtieron en comunas, con un sistema de regulación de paz y de recaudación impositiva que les fue confiriendo la fisonomía burguesa. No obstante, reconoce que dicha estructura identifica clásicamente a las ciudades de raigambre latina, ya que en otros territorios la fundación dependía de un príncipe y allí quedaba 
suprimida la violencia que acarreaba el origen. Es semejante arrastre violento el que España transfiere a sus colonias americanas, y así como resultó efectivo en el sepultamiento de la capital azteca para dar paso a la ciudad hispánica de México, recibió la sanción inmediata de la resistencia indígena cuando dispuso establecer Buenos Aires a orillas del río de la Plata en 1536.

Lo que no llegó a América fue ese afán de reproducir en la tierra la visión celeste de San Juan que representó el arte gótico esparcido en catedrales que embellecían y distinguían las ciudades, promoviendo una competencia entre ellas. Pirenne sostiene que la reunión del espíritu religioso que alienta en esas construcciones y el impulso laico que las lleva a cabo no solamente es producto de la explosión ciudadana medieval sino que además fomentaría los dos grandes movimientos de ideas de la etapa siguiente: el Renacimiento secular y la Reforma religiosa. Vehemente en la Contrarreforma, España trasladó de inmediato a América la intolerancia inquisitorial pero sólo tardíamente el estilo soberbio y engreído que reemplazó los afanes ascendentes del gótico por el ansia exhibicionista de poder y riqueza: el barroco. Una hipótesis sugestiva de Ángel Rama, que no prosperó por haber quedado relegada a un artículo recogido tardíamente (2006), es que el barroco constituye un producto americano, ya que sin la riqueza mineral hallada en estos territorios hubiera sido impensable ese fraude esplendoroso de los europeos.

La ciudad barroca se resumió en pura fachada. Para eso se entregó a ornamentar los frentes hasta la sobrecarga, interiorizando todo lo que no participara del estilo ostentoso. La mayor resistencia al barroco americano la constituyen las edificaciones jesuíticas que optaron por una presentación austera para lanzarse a los excesos en el orden de la orfebrería. Altares, pebeteros, cálices y custodias confirman la dedicación de la Compañía de Jesús al propósito único de adoración prescindiendo de sofisticaciones de mampostería. Ad Maiorem Dei Gloriam es la divisa que refulge en esos objetos hoy reunidos en los catálogos del plateresco. La autonomía política con la que operaban los jesuitas en sus reducciones, explotando a los indios a quienes evangelizaban y proveyendo a la propia Compañía antes que al Es- 
tado español, motivó su expulsión del territorio americano, aunque lo suficientemente postergada como para que dejaran instaladas las bases del sistema educativo en colegios y universidades.

Las construcciones de la ciudad barroca -que proseguirán en las adaptaciones que ejerza sobre ellas el estilo virreinal, para recalar en la obra pública que adoptó los rasgos del neoclásico ya en el siglo XIX- exceden desde el comienzo el funcionalismo para presentarse en términos artísticos. Lo mismo ocurre con el trazado urbano que oscila entre dos formas excluyentes: la cuadrada que reproduce la simetría corporal en su disposición (Sennett 25) y que domina en las sucesivas réplicas que la Roma quadrata registra en el orden latino de manzanas homogéneas, y la circular que es más propia de las urbes protestantes, tendientes a la extensión radial del ejido a partir de la iglesia. El mundo romano privilegió una estructura dominada por el poder terrenal y apta para el control mediante la cuadrícula; el orbe germano sostuvo su despliegue a partir de la presencia omnivigilante de Dios en el centro de un círculo cuya circunferencia proveyeron las murallas defensivas, luego derribadas y convertidas en avenidas de circunvalación. La disposición cuadrada o rectangular favorece la perspectiva porque permite la dramatización del espacio, que abandona su papel de otorgador de jerarquías para mutar en sistema de magnitudes (Mumford 38).

En América ese cambio en el espacio fue consecuencia del reemplazo de culturas que se operó con la llegada de los españoles. De allí que la cultura urbana se opusiera inicialmente a la de concentraciones menores como las aldeas en que se refugiaban las culturas arrasadas e incluso a la de zonas geográficas precisas donde la supervivencia y la salvaguarda de los desplazados era posible merced al aislamiento, como ocurría en regiones montañosas. No obstante, la sierra peruana marcará una asimetría en tal sentido: si bien la población indígena logró concentrarse allí, la codicia hispánica se entrometió en las organizaciones comunales para aplicarles no ya la modernización europea sino las prácticas perimidas del feudalismo, cuya liquidación respondía al avance burgués. La idea de una explotación puramente campesina había dejado de ser útil en una Europa que entendía la integración 
como requisito de subsistencia; eso redundará en la observación de Raymond Williams (2001) según la cual los suburbios se vuelven las zonas realmente peligrosas para la ciudad.

El momento de nacionalización de la cultura urbana en América corresponde a la etapa independentista, cuando los dirigentes locales imponen una regla que, con muy pocas excepciones, se cumple en la tradición latinoamericana: la de resumir toda la nación en la capital o, en ocasiones, en la ciudad principal cuando una y otra no coinciden. Los ejemplos de "capitales pareadas" que despliega América Latina, si inicialmente dependen de la tensión entre la metrópolis indígena y la ciudad hispánica -los casos de Cuzco y Lima, o de Guayaquil y Quito-, también responden a conflictos internos -Sucre, capital constitucional de Bolivia establecida sobre la antigua Chuquisaca, cedió el asiento gubernamental a La Paz- o a rivalidades que no logran aplacarse. Es lo que aconteció cuando la enemistad indeclinable entre Río de Janeiro y San Pablo despojó a ambas de los atributos de mando derivándolos a la artificialidad de Brasilia, de la cual se esperaba que pudiera integrar el Mato Grosso al resto del país. Nada de eso sobrevino: la selva mantuvo su fisonomía indómita y el encono de las otras ciudades persistió con vigor redoblado.

Ningún método mejor que el recorrido para asomarse a las ciudades latinoamericanas. Ante la imposibilidad de cubrirlas in extenso he escogido un recorte que procura dar cuenta de algunas fisonomías: por un lado, las grandes capitales virreinales que fueron Ciudad de México y Lima, centros de las secciones políticas más importantes que la Corona hispánica creó en América. Su vínculo con el pasado está lastrado de determinismo en un caso y de tradición en el otro; su relación con el futuro es incierta, como todas, pero existe una tendencia de quienes la han interrogado a pronunciarse por el pesimismo, como si los desmanes pretéritos permanecieran fijados y reapareciesen en cada vuelta de la historia. Por el otro lado, dos ciudades sucesiva y vehementemente modernizadas como Buenos Aires y Río de Janeiro. En la capital del virreinato menor del Río de la Plata, cuya fundación tardía no tuvo más propósito que impedir o al menos reducir el contrabando con la zona portuguesa, el enfático desdén porteño hacia el interior todavía sigue 
definiendo a Buenos Aires como seudoeuropea orgullosa de una prosapia impostada. Río de Janeiro, por su parte, compitió con la metrópoli rioplatense horadando y arrasando parte de la topografía local hasta revelarse como espacio de contrastes en que la bahía y los morros, el mar y la favela concitaron los intereses de un turismo superficial que ignora en la belleza despreocupada de las playas de Copacabana la raigambre de la urbe creada bajo los auspicios de San Sebastián.

\section{Ciudades virreinales: de la fundación a la denegación}

"Viajero, has llegado a la región más transparente del aire" (Reyes 13), declara el epígrafe de Visión de Anáhuac (1915) de Alfonso Reyes, otorgando resonancia a la frase atribuida al barón de Humboldt cuando arriba a la meseta mexicana. Sin embargo, no es la perspectiva del viajero la que reivindica esta evocación de Tenochtitlán-Tlatelolco, sino la del emigrado al que acosan nostalgias de la cornucopia vegetal agredida por la desecación del lago de Texcoco. El avance del desierto no afectó los alardes heráldicos de un paisaje que metamorfoseó la "flora emblemática" (14) en "aristocrática esterilidad" (17).

Atenuando el interés casi exclusivo que recibió Tenochtitlán como sede del imperio azteca por su condición militar, Reyes apunta hacia el mercado que ocupaba la vecina ciudad de Tlatelolco, allí donde se alzaba el fantástico palacio de Moctezuma en el cual es posible intuir los grabados esqueléticos de José Guadalupe Posada y anticipar el desborde de prodigios que abarrota las películas filmadas por Buñuel durante su estadía mexicana. El "sueño de Brueghel" (22) que marea los sentidos se extiende hacia la colección desaforada en que coexisten "familias de albinos, de monstruos, de enanos, corcovados y demás contrahechos" (26), como en el comedor caritativo de Viridiana (1961). Los aposentos del cacique se perfilan como Wunderkammer que inspira la poesía americana, la de Netzahuacoyotl tanto como la de Rubén Darío cuando alucina a Moctezuma en la silla de oro.

Tlatelolco fue anexada a Tenochtitlán apenas los españoles decidieron extender los límites de la ciudad. Semejante vocación amplificadora contrariaba la voluntad azteca de cerrar la urbe y escatimar la ciuda- 
danía, prefiriendo el sometimiento de los vecinos a la integración. El afán expulsivo persiste tanto en los ejercicios novelísticos como en los antropológicos que toman a México como epicentro en La región más transparente (1958) de Carlos Fuentes y Los hijos de Sánchez (1961) de Oscar Lewis. El libro del profesor norteamericano que convirtió a la familia misérrima del Zócalo en informantes académicos elaboró el concepto original de "cultura de la pobreza" para definir la vida sin recursos en medio de la ciudad que convida al consumo constante. La vecindad ubicada a metros de la sede del poder reproduce así en términos espaciales el escándalo lógico que trasunta el nombre del Partido Revolucionario Institucional (PRI).

Lewis se lamentaba de no poder cumplir su trabajo con el respaldo que en otra parte le hubiera brindado una frondosa tradición novelística a partir de la cual recomponer la historia social de los habitantes urbanos. Pero su queja respondía antes al desconocimiento de la literatura mexicana que al acierto de la observación. Precisamente esa región fue la que produjo la primera novela que logró publicarse en América al cabo de una sostenida prohibición que abarcó tres siglos, El periquillo sarniento (1816) de José Joaquín Fernández de Lizardi. A cuenta de la veda sobre la literatura ficcional en el continente hay que cargar la circunstancia de que la obra de Lizardi sea un ejemplo de picaresca, género que había registrado su éxito mayor en Europa durante las primeras décadas de la conquista. Pero como este dato puede redundar en asincronía perversa que alimente la idea del atraso americano, conviene relegarlo para detenerse en el carácter pionero que lo convierte en cabeza de una serie novelística que indaga aspectos de la ciudad. El pícaro de Lizardi encuentra su descendencia narrativa en los bandidos de Manuel Payno para proseguir ya en el siglo XX en los pecadores de Federico Gamboa, los revolucionarios de Martín Luis Guzmán, los obreros de José Revueltas y el dandysmo criminal con que Rodolfo Usigli (Celorio XXIV) obsequió las inclinaciones perversas de Buñuel.

La sucesión condensa en La región más transparente el Breviario del Nuevo Mundo de Humboldt y la Visión de Anáhuac de Reyes, sumadas a la síntesis mural de Diego Rivera en Sueño de una tarde dominical en 
la Alameda central (1947) (Pacheco XXXV) y apela a la inversión del México rural que, después de transitar el estereotipo diseñado por la novela de la Revolución, desemboca en la manifestación lacónica e insuperable que es Pedro Páramo (1955). Los "guardianes" de la novela de Fuentes, Ixca Cienfuegos y Teódula Moctezuma, están más próximos a los personajes de Rulfo cuando mutan el comal en Comala para alegorizar el infierno terrenal, que al taxista y la prostituta que se erigen en testigos supraclasistas e interbarriales del Distrito Federal.

Abundando en una postura que domina en los autores convocados en esta exposición, Fuentes procura comprimir en la capital todo el país, y lo hace a la manera balzaciana, con un conjunto de personajes en que confluyen no solamente las aspiraciones sociales sino también los momentos más sobresalientes de la historia nacional. Así, el conde Lemini recuerda a los texanos enriquecidos que ilustran alguna página de México insurgente (1913) de John Reed, Estévez es un émulo de José Gaos en su rol de introductor de Heidegger en México, Librado Ibarra como abogado sindical acude al leve desvío de la figura de Librado Rivera, compañero anarquista de los hermanos Flores Magón, y algunos personajes quedan modelados por episodios puntuales. De este modo, los de Ovando son antiguos porfiristas que no soportan el orden posrevolucionario y añoran la ciudad donde las mansardas "como un escudo hablaban a todos de rango, de gusto, de propiedad" (Fuentes 2008 99), y Federico Robles es un ejemplo de self made man a quien el gobierno de PRI volvió exitoso y le concedió una oficina sobre la avenida Juárez.

La ciudad de La región más transparente ratifica el aserto de Lewis Mumford (221) según el cual toda megalópolis contiene su propia destrucción. Un contexto de derrotados desmiente la aureola refinada del Paseo de la Reforma, en cuyas adyacencias "las mansiones del porfiriato iniciaban su declive hacia la boutique" (Fuentes 2008 67). La "ciudad de los palacios", como la recuerda el título de uno de los capítulos, se contrajo en metrópolis de departamentos que profesan una cultura abigarrada e inconexa donde con idéntico desparpajo cuelga en una pared un cuadro cubista y se esparcen por el piso reproducciones enanas de la Coatlicue. Para conjurar la superficialidad de 
la burguesía colonizada, Ixca acude a realizar un ritual de desentierro con las calaveras que conserva Teódula y luego se lanza al Zócalo, recorriendo el Palacio, la Catedral y el Ayuntamiento, entre "piedras rojizas y marfil gastado" (285).

Es allí donde descubre, a la par de las máscaras que portan los personajes en un intento desesperado de anular la calavera que las sostiene, las raíces de esa ciudad a la cual el oropel no consiguió desprender de su origen bélico y sacrificial. Ixca repone la fundación trágica que alienta en la ostentación afrentosa, recupera los castigos aztecas por encima de la traición de la Malinche y, en su condición de figura agorera, apunta a la historia nefasta por la cual el Estado mexicano liquidó a sus propios jóvenes en la masacre de la Plaza de las Tres Culturas el 2 de octubre de 1968.

La ciudad mercantil que había sido Tlatelolco durante el esplendor azteca, aquella en la que refulgía el palacio de Moctezuma, quedó reducida a mero suburbio de la Ciudad de México y luego a barrio bruscamente modernizado, donde la pirámide aterrazada convive dificultosamente con esas moles de cemento que son los monoblocks del complejo Nonoalco. En su apostura de colmena rígida se agazapa el crecimiento desmesurado de una capital que, sumando la zona metropolitana, supera los veinte millones de habitantes. La plaza reúne tres momentos de la historia mexicana: el azteca con el teocalli, el colonial con la iglesia de Santiago Tlatelolco y el moderno con la disposición del conjunto.

Allí confluyeron los estudiantes de la UNAM y del Instituto Politécnico, que reclamaban un diálogo con el gobierno empeñado en monologar, y la participación en el manejo de la propia universidad. Los ecos del Mayo francés con su impulso desenfadado azuzaban los ánimos, que recibieron el día de la marcha una sanción más propia de la Primavera de Praga que de la imaginación al poder. Una bengala restalló en el cielo como señal que disparó la descarga de fusilería del Batallón Olimpia, asistido por francotiradores. El grupo de tareas llevaba ese nombre porque pocos días después se iniciaban en México los Juegos Olímpicos, en una demostración ingenua del progreso nacional. Los periodistas cosmopolitas enviados a testimoniar el desarrollo termina- 
ron denunciando el espectáculo de ejecución que Elena Poniatowska recompuso en La noche de Tlatelolco (1971).

El libro se propone como una crónica de los hechos que se inscribe tanto en el marco de la Visión de los vencidos como en el del Memorial de Agravios de Camilo Torres, reeditado por Rosario Castellanos en el "Memorial de Tlatelolco", ofuscado en una dialéctica de oscuridad y violencia. La explanada con escalinatas se reveló topografía ideal para la encerrona. "El paisaje mexicano huele a sangre", había advertido Eulalio Gutiérrez en medio de la Revolución; en 1968, la frase adquiría una actualidad desgarradora. Con tono oracular, mediado por epigramas de vocación axiomática, lo advierte Octavio Paz en Posdata (1969), aunque sometiéndolo a una despolitización alarmante: el gobierno había llevado adelante un "ritual de expiación" (Paz 41), retornando a las raíces aztecas en las cuales los dioses reclamaban sangre desde la pira del sacrificio.

Tal esencialismo se esforzaba por mitificar la geografía y la historia, y así como hacía de los estudiantes unos bandoleros descontrolados hasta rozar la revuelta -"Nadie quiere una revolución sino una reforma” (35), pontifica-, estigmatizaba a los campesinos en tanto supervivencia y excrecencia: "Nuestro único vínculo con el neolítico, esa edad feliz que apenas si conoció al monarca y al sacerdote, son los campesinos" (88). Tlatelolco es el retorno de lo reprimido anunciado por la persistencia de la pirámide que Fuentes ve replicada en la estructura piramidal del PRI (Fuentes 1972 148). Y aunque inicialmente asocia a Díaz Ordaz con otro Díaz, Porfirio, Fuentes también cae en la tentación metafórica por la cual los Juegos Olímpicos son "la otra cara de la guerra florida" (153) y se lanza a hacer del presidente el Tecatecuhtli de los aztecas.

La voz crítica se encarna en Carlos Monsiváis, quien incrédulo de los aspavientos de los mayores denuncia el anacronismo allí donde Paz y Fuentes lo disolvían con el expediente facilitador del "tiempo mítico". En su crónica intemperante, cuya sintaxis urgente de oraciones breves acelera los datos, quedan reunidos el "cuerno de la abundancia" mexicano (Monsiváis 2000 224) de Reyes y las explicaciones irrisorias de los otros escritores. Una filigrana de ironías logra rescatar las consignas estudiantiles detrás de los slogans que propaga la prensa, 
proponiendo un equilibrio entre la quietud del tiempo vacío del mito y la velocidad de la cronología trivial en que incurre el periodismo oficialista. La crónica se revela gracias a estos recursos un género tan urbano como el policial e igualmente propicio para dar cuenta de las alternativas de una ciudad.

Así se inscribe en Lima desde la mirada desenfadada e irreverente que le dedica Mario Vargas Llosa en Conversación en La Catedral (1969), cuyo protagonista es el periodista del diario La Crónica entregado a la página policial justo cuando su propia familia aparece involucrada en un crimen. Pero antes de llegar a esa novela, antecedida por una aproximación igualmente descarnada del escritor a la capital como síntesis nacional y foco narrativo (La ciudad y los perros, 1963), hay un conjunto de autores que hicieron del altivo centro del virreinato del Perú el objeto de sus indagaciones, abonando tanto a lo estético como a lo político.

La nómina comienza con Juan del Valle y Caviedes, quien en su drama Coloquio entre la vieja y Periquillo sobre una procesión celebrada en Lima retoma la figura del pícaro que recorre la ciudad en el siglo XVII. Le sigue Concolorcorvo, cuyo orgullo limeño habilita la comparación justificada por el viaje de un funcionario- entre el virreinato poderoso y la nueva jurisdicción del Río de la Plata pródiga en pobretones y gauderios a fines del siglo XVIII. Ya en el XIX continúa con las Tradiciones peruanas de Ricardo Palma que han sido la argamasa más efectiva para erigir el monolito de la Arcadia colonial. En el siglo XX avanza con José Carlos Mariátegui quien, aunque reivindica la sierra como futuro socialista del Perú, cumple labor de intelectual urbano con Amauta. La serie llega en los mismos años 60 en que escribe Vargas Llosa a la desolación sarcástica que desgrana las páginas de Lima la horrible (1964) de Sebastián Salazar Bondy.

El ensayo descorazonado procura desarticular el linaje pretencioso de la Colonia utópica. Lima luce como un México desapasionado: virreinato más acotado, cuya organización indígena inclusiva fomentada por el imperio inca repudia el énfasis excluyente de los aztecas, el caso limeño recibe el diagnóstico degradante de "malinchismo en almíbar" (Salazar Bondy 15), recaída edulcorada cuya insignia no es 
la traidora indígena sino la diva local Perricholi. El criollismo intimida con su catálogo de negatividades: es un tradicionismo sin costumbres que lo sustenten, una pretensión de nacionalismo imbricada en la metrópoli, una formulación cortés de la abominable "viveza criolla" que coordina "inescrupulosidad y cinismo" (27).

La ciudad que cobija tales defectos se impregna con ellos: por un lado, es femenina "porque la opresión opera aquí de modo femenino" (78), solapando el poder de la mujer en la fachada legalista del matrimonio. Por el otro, su feminización no es como la que reconocía Mumford en las ciudades que exhibían una faz lustrosa de vidrio y acero (Mumford 194) frente a las urbes masculinas hechas de portland, sino que prolifera en espacios de "caótica arquitectura donde el tudor y el neocolonial se codean con el contemporáneo" (Salazar Bondy 49). La vocación integradora de los incas desciende aquí al conglomerado de horrores en que coinciden la barriada clandestina, el corralón rústico y el callejón cuya equívoca guardia de honor componen los tugurios que lo flanquean.

Contra el México en que la tragedia derivaba en afrenta, en Lima cualquier dramatismo se resuelve en sátira, forma comedida y condescendiente de la crítica. No adquiere la forma directa y decidida del insulto sino la sesgada y colateral de esos ejercicios verbales apenas provocativos y nunca directamente hirientes que se profesan mediante la lisura y encuentran su manifestación estética más ajustada en la huachafería, snobismo que participa de la misma tolerancia insustancial que registran otras alternativas de contacto social.

La atención excesiva que merece Lima en estos autores arrastra como correlato el desinterés casi absoluto hacia los indios. Las excepciones de Manuel González Prada y de Mariátegui no alcanzan a contrarrestar la ausencia de una población que en Vargas Llosa ingresa lateralmente, ya sea en los serranos de La ciudad y los perros, ya en el horror del senador Zavala ante la "cholería infecta" que condena en la Universidad de San Marcos en Conversación en La Catedral. Pero el verdadero vocero de las tradiciones incaicas es José María Arguedas, sobre todo a partir del desplazamiento que obsequia a la centralización limeña a fin de recuperar la capital prehispánica. 
Los ríos profundos (1958), con su reivindicación cuzqueña de piedras soberbias, es tal vez la causa de esa respuesta capitalina que radica en La ciudad y los perros. La admiración de Vargas Llosa por el intelectual transculturado que es Arguedas se verifica a la vez en la conversión del colegio de curas en liceo militar y en la atribución de dotes escriturarias al protagonista, que despeña la sensibilidad poética de Ernesto en la profusión pornográfica de Alberto. La escena del desfile militar duplica la que se relata en Los ríos profundos, y si allí acudía a contrarrestar ingenuamente la fuerza de las chicheras alzadas, en La ciudad y los perros se reduce a pura parafernalia cuyo propósito aspira a desmentir en el rigor exclusivamente escenográfico los estigmas vengativos del ejercicio de guerra en que resulta asesinado un cadete.

Mientras la obsesión de Arguedas descubre la cultura sepultada bajo las capas de colonialismo, la de Vargas Llosa se enfrasca en indagar "en qué momento se había jodido el Perú" (Vargas Llosa 2010a 15) y por qué el país se empecinaba en el "color caca" (20) de Lima. En la ciudad de garúa sin lluvia, de techos chatos desprovistos de relieves y perspectivas, el recorrido urbano va marcando estaciones de resentimiento como las que afectan a Hortensia en su desbarrancamiento. La ciudad progresivamente hostigadora para la prostituta de Conversación en La Catedral es el espacio inhóspito al que arriba el Esclavo Arana en La ciudad y los perros para ser liquidado hacia la mitad de la novela. La urbe en que campean los nombres de los héroes de la Guerra del Pacífico, salpicados con algunas fechas históricas y cierta concesión a Manco Cápac, ilustra la ciudad letrada que los "sabios limeños" de Concolorcorvo celebraban desde la llustración para estrellarse en el ridículo de la capital inauténtica que escandalizó a Salazar Bondy.

\section{Ciudades modernizadas: del fin-de-siècle a la globalización}

Un escándalo similar, el del puritano en el burdel, afecta a Ezequiel Martínez Estrada cuando encara la ciudad de Buenos Aires en La cabeza de Goliat (1940). Pero el encono de este profeta del escepticismo no es el arranque de un sujeto ofendido sino la consecuencia de una 
reflexión que comienza para él en Radiografía de la pampa (1933) y el resultado de una serie de literatura porteña que en las primeras décadas del siglo XX traza un catastro que asigna a cada escritor una zona urbana. Así, Héctor Pedro Blomberg se ubica en el puerto para imaginar los amores turbulentos de los hombres de mar, Raúl González Tuñón ronda esos confines de la ciudad para ir adentrándose en un centro igualmente sórdido y Manuel Gálvez se enfoca en el barrio de La Boca para definir el alcance de la zona fronteriza en Historia de arrabal.

Otros arrabales frecuenta Jorge Luis Borges, quien bajo los auspicios de Evaristo Carriego se proclamó feligrés exclusivo de la parroquia de Palermo donde conviven compadritos y conversadores, corralones y patios. Apelando a la misma época de cuchilleros que desconocían el manejo del arma de fuego, Leopoldo Marechal otorgó categoría estética a los barrios desatendidos de Villa Crespo, más céntrico, y de Saavedra, en el límite difuso que la ciudad impone desde los caprichos geométricos que hicieron de la Avenida General Paz la última estribación porteña. Más cerca de Villa Crespo tanto por geografía como por cultura, César Tiempo se entregó a Balvanera, zona popularizada como Once y de adscripción nítidamente judía hasta que las migraciones orientales, primero, y de países limítrofes luego, desbordaron a la colectividad. Oliverio Girondo, en cambio, optó por poetizar el barrio de Flores, donde las muchachas cortejaban más la calle que a los hombres desde la condición de palco privilegiado ofrecida por el balcón de hierro.

En la misma zona de Flores donde se crió, Roberto Arlt situó su primera novela, El juguete rabioso (1926), para volver a fijar su atención poco después a través de las Aguafuertes porteñas publicadas en el diario El Mundo, cuya crítica aparece impactada por la condición corrosiva de los ácidos empleados en esa técnica pictórica. "Molinos de viento en Flores" añora el barrio donde toda la modernidad se resumía en el ferrocarril, pero tal mirada nostálgica queda suficientemente recortada como para revertirse en lamento por la falta de modernización en "Grúas abandonadas en la isla Maciel" o solazarse en la identidad invulnerable de la calle Corrientes pese al ensanche que sufre para derivar en avenida. 
La impronta de las Aguafuertes porteñas, con su vocación de estampa y su impregnación de presente, resuena en los capítulos breves de $L a$ cabeza de Goliat, aunque Martínez Estrada no se regodea en filología lunfarda como Arlt, ni en tipos urbanos que hurtan el cuerpo y la voluntad a toda labor, sino que prefiere la forma brutal del latigazo para moldear los fragmentos de su ensayo, recayendo a menudo en la tendencia axiomática que condena sin apelación y convence no por la fuerza del argumento sino por la perfección de la retórica. La figura del Sócrates porteño que hace de la denuncia una obligación cívica se expande en principismo desaforado en el que la regla es la perversión porteña. La cabeza desproporcionada para el cuerpo exánime, replicada en la red de transportes que indefectiblemente conduce a la capital, desafía incluso la geometría, de modo que el trayecto más breve entre dos puntos de la Argentina deja de ser la línea recta para ser el paso por Buenos Aires.

Ciudad de primer piso, con una perspectiva sesgada por esa mínima distancia respecto del suelo, no hay escándalo que no prospere bajo su amparo: en ella la urgencia del traslado corresponde al colectivo que cubre recorridos menores y no al tren que cumple largos trayectos; allí los cambios no tienen la decantación botánica de siglos que demandan los europeos sino la velocidad americana de una metamorfosis de insecto; en sus límites la demolición reemplaza el afán de cambio por el de compensación; fue construida en función del puerto pero se empecina en darle la espalda; su división mayor no es entre ricos y pobres como en el trazado Norte-Sur sino entre céntricos y marginales según el eje Este-Oeste; ostenta la paradoja de una legislación perfecta incapaz de corregir cualquier conducta y su literatura comprende menos la originalidad de esos datos que la vocación desviadamente mimética de la traducción errónea, que afecta tanto la novelística de Arlt como los ejercicios de provocación que cumple Borges en Historia universal de la infamia (1933).

Lo que se desprende de estas apreciaciones es el reconocimiento de la prensa como voz urbana, sumado al policial como género catártico. El héroe de la ciudad es el destructor, el que transgrede las normas, el que abandona el caballo para subirse al automóvil pero aplica dentro de 
la carrocería la habilidad corporal del jinete. Las calles desprovistas de pavimento no son un resguardo frente a la uniformidad asfáltica sino un síntoma de que lo reprimido se encuentra en acecho, agazapado con la violencia de la pampa que amenaza cuando en las junturas de los adoquines crece un yuyo silvestre que descree por igual de la edificación y de la convivencia forzada en la vecindad, el conventillo o el barrio.

Acaso contagiado por una figura borgeana en cuyo éxito superlativo late su misma anulación, Martínez Estrada convierte a Buenos Aires en el Aleph del país. Pero esa esfera en la que se encuentra compendiada la urbe completa no puede percibirse en forma directa sino a través de sustitutos ortopédicos (Gorelik 37) elevados a auxiliares y símbolos de la ensayística destemplada. El Aleph de La cabeza de Goliat deplora la incidencia hispánica sobre el territorio pampeano porque añade un nuevo fracaso al que ya trasuntaban la llanura homogénea e ilimitada y los indios irrelevantes del sur frente a la magnitud de los imperios azteca e incaico.

Sin embargo, en el Brasil de los mismos años, la presencia de España en América no es percibida con idéntica desazón. Al contrario: para Sérgio Buarque de Holanda, quien indaga la formación social del país en Raízes do Brasil (1936), la colonización hispánica tuvo rasgos de organización y planificación sensiblemente superiores a la portuguesa. Acudiendo a los tipos ideales de Max Weber y a una fuente común con Martínez Estrada, la de George Simmel, Buarque se empeña en una dicotomía que no siempre mantiene el esquematismo ni es necesariamente tan tajante como pretende.

Según el recuento de Buarque, los españoles tendieron a fundar ciudades en la proximidad del mar o bien siguiendo los cursos de los ríos, en tanto los portugueses procuraron avanzar hacia el interior con grupos liderados por un pionero que recibió el nombre distintivo de bandeirante. Sin embargo, las ciudades que operaron como capitales sucesivas del territorio brasileño se ubicaron en el litoral marítimo: Salvador de Bahía, que cumplió esa función hasta 1763, y Río de Janeiro, declarada capital para vaciar hacia la metrópolis lusa las riquezas mineras de la zona próxima de Vila Rica, luego devenida Ouro Preto, en el estado vecino de Minas Gerais. 
La historia de la fundación de Río fue elevada a épica nacional en $A$ Confederação dos Tamoios de Domingos José Gonçalves de Magalhães. El poeta romántico transmutó la circunstancia histórica de la creación carioca en mandato divino, lo que resulta congruente con la decisión del sacerdote José de Anchieta de fijar el dominio sobre el mar en 1565, despojando a los franceses de ese asentamiento. Anchieta había establecido la villa de Piratininga el año anterior, una misión jesuítica que devino la actual ciudad de San Pablo.

No está en mi ánimo ocuparme de la rivalidad entre Río y San Pablo. Baste señalar que la primera tiene una prosapia estética más imponente que encuentra su ícono en la garota de Ipanema en tanto San Pablo ostenta la condición de ciudad más poblada y más rica de Latinoamérica, con un relieve literario cuyo epicentro es el Modernismo de 1922 con sus secuelas. La cidade maravilhosa que despliega fascinada la vista sobre la bahía de Guanabara e impone la perspectiva aérea desde el Cristo redentor es reconocida como "ciudad global" en los términos establecidos por Saskia Sassen, para lo cual debió ajustarse a una serie de cambios iniciados entre fines del siglo XIX y principios del XX, cuyos cronistas mayores fueron Olavo Bilac y João do Rio.

Bilac recuperó la actitud ambigua que Anatole France destinaba a los ejercicios críticos: es así como la mirada que este "príncipe de las letras" brasileño dedica en 1916 a su ciudad natal se titula Ironía e Piedade. Una traducción insolente publicada en Buenos Aires en 1952 desdibujó la dualidad del enfoque para reducirla a tarjeta postal con la infame insignia de Estampas de Guanabara. Lo que no se diluyó en tan aberrante traslación fue el entusiasmo del cronista que desafió a la Atenas del Plata porteña con la Acrópolis ufanista de la Gazeta de Notícias, cuyo edificio en la Rua do Ouvidor -la calle selecta de Río, aquella donde la sede de Garnier definía el itinerario restringido y aristocrático de Machado de Assis- exhibe "las dos puertas de oro de la fama y de la gloria" (Bilac 23).

La atención de Bilac a los edificios es correlativa de la que presta a los objetos, donde sobresalen las campanas que trocaron la función criminal que les asignó Europa para lanzarse a la relajación en la ciudad brasileña: en lugar de convocar a la masacre de San Bartolomé, los 
carillones eclesiásticos "se pusieron a acompañar los tangos indecentes, las polcas lascivas, las innobles 'machichas', prostituyendo la voz destinada al servicio divino" (35). Esa fijación por las fachadas que acompaña el peregrinaje del cronista urbano es un fenómeno exclusivamente diurno, ya que por las noches no es la soberbia edilicia la que se impone sino que, como al mirar a un sujeto cuando duerme, desprovisto de hipocresías y con las líneas de expresión relajadas, las casas "que parecen nidos al sol" reservan para las horas de oscuridad "su verdadero aspecto de catacumbas..." (46), más próximas a la necrópolis que al exhibicionismo turístico.

El observador condensa las perspectivas urbanas de argentinos y brasileños contemporáneos. Como el Borges que cifraba en las inscripciones de los carros el origen de la literatura nacional, Bilac se extasía en los carteles de los negocios para tributar a la mitología urbana derramada en hojas periódicas, en crónicas efímeras, en anuncios pasajeros. Frases perfectas en su brevedad de anatema se alzan en los frentes comerciales con el efectismo de la construcción nominal que desvanece las acciones y provoca una fijación inmediata: "El Farol del Baratijero", "El Atalaya de los Parroquianos", "La Estrella del Buen Tocino" o "El Heraldo de la Carne Seca" contienen un convite en su misma designación, aunque a diferencia del juicio entusiasta que Borges reservaba a tales fórmulas espontáneas, Bilac las condena por producir "esta ilusión de delirio vesánico: la existencia de una literatura nacional en un país que no sabe leer" (159).

La voluntad de admitir a Río como federación de ciudades y país trazado a escala requiere una variedad de pobladores que, si no resultan representativos de las regiones nacionales, sí lo son de los barrios que integran el conjunto. En ellos la solidaridad responde menos a la vocación humana de asistencia mutua que a la comunicación interbarrial cuyo modelo proveen los perros, impregnados de rasgos cervantinos en su profusión coloquial. La utopía canina del "falansterio de los perros" (99) hace de una calle de arrabal "su ágora, su fórum, su gimnasio" (Ibid.) y de sus diálogos frecuentes una advertencia sobre las asechanzas ciudadanas, eludiendo la acción de la perrera mediante la prensa de ladridos que se expande por Gávea, Tijuca, Jacarepaguá. 
El punto que unifica a Bilac con Arlt es el de los tipos urbanos. En las Aguafuertes porteñas campean quienes renuncian a toda tarea: el squenun que expone con desenfado su haraganería, el furbo que estafa a los conocidos con el chantaje irresistible de la simpatía, el que se tira a muerto con un desinterés insobornable por cualquier colaboración, el hermanito coimero que se entrenó como vago explotando a sus futuros cuñados ante la amenaza de revelaciones impropias, el enfermo profesional que recorre la cartilla médica buscando un especialista en cada uno de los múltiples síntomas que lo aquejan. En las crónicas cariocas la galería es más variada y ocasionalmente condesciende a cierto costumbrismo, si bien evitando la recaída en él. Los "Tipos populares" son "celebridades grotescas" que no llegan al delirio doble de los cartomantes: el de ellos mismos, "Charlatanes del Más Allá" -a quienes Arlt abordaba con una curiosidad más próxima a la fe que a la suspicacia en "Las ciencias ocultas en la ciudad de Buenos Aires" (1920)-, y el de la policía que los persigue con la excusa del "saneamiento moral" (185). Como en el caso de los jugadores clandestinos que se entregan a los bicheiros -lotería ilegal cuyos explotadores llegan hasta el Río de los años 50 que describe Rubem Fonseca en Agosto (1990)-, Bilac se impacienta y concluye que es imposible "exterminar la raza de los tontos" (189), reduciendo a capacidad intelectual limitada la desesperación crédula de sus conciudadanos.

Otros tipos visita João do Rio en las impresiones que constan en $A$ alma encantadora das ruas (1908). Allí se agolpan las "Pequeñas profesiones", los tatuadores, los vendedores de libros, los músicos ambulantes, los cocheros viejos, los estibadores y las mendigas. Pero como la galería de personajes es frecuentada por varios cronistas y admite variantes ilimitadas, la originalidad de João do Rio apunta a las particularidades de la calle que "nivela y agremia" a cronista y lectores en una fraternidad indisoluble. La tendencia a la filología lunfarda que practica Arlt parece desprendida de la promoción de la lengua babélica que reconoce João do Rio en la fenomenología de la calle que acomete en la crónica " $A$ rua". Es con él -en la línea sarmientina- con quien el extranjerismo del flâneur se acriolla en el verbo "flanear" traducido como "deambular con inteligencia" (Rio 28). El espíritu que Arlt atribuye a la calle Corrientes es aquí "alma" 
callejera que, sin renunciar a un moralismo convencional, abarrota de atributos las arterias más recorridas de la ciudad. Así, la Rua do Ouvidor "es la fanfarronada en persona" y soporta "la especialidad de la bravata" (30), la Rua da Misericórdia es el origen carioca y "de ella brotó la ciudad" (31), y hay otras que no arrastran estirpe sino que surgen improvisadas por la mano modernizadora de un prefecto, como las que "cambian de lugar, cortan morros, van a acabar en ciertos puntos que nadie antes imaginara" (Ibid.).

La percepción decadentista a la cual se ajusta João do Rio en la serie francesa de Jean Lorrain lo lleva a comulgar con la revelación nocturna a la que adhiere Bilac: "El alma de la calle sólo es enteramente sensible a horas tardías" (33). Pero en do Rio, más que el esteticismo de raigambre romántica que persiste en Bilac, es el afán modernizador el que impera, por el cual reconoce que la calle es un desprendimiento de esa urgencia por trazar caminos que encuentra en la ruta su emblema principal. La calle derivada de la carretera ingresa a la ciudad para imponerse sobre el barrio, de modo que la conducta domine sobre el trazado y el estilo sobre la cuadrícula. La calle es la ruta provista de personalidad, adecuada a los avatares de quienes la transitan: así, en Botafogo Julieta espera a Romeo, en tanto en Cidade Nova, Julieta se presta a la seducción múltiple al colgar sus pechos del balcón, enlazando con el Girondo de los Veinte poemas para ser leídos en el tranvía (1922).

El enfrentamiento de Río de Janeiro y Buenos Aires, que ofuscó al prefecto Pereira Passos hasta modificar la fisonomía carioca derribando morros y a los sucesivos dirigentes imponiendo el uso de zapatos y la aplicación de vacunas para emular a la soberbia capital porteña, revela así su afinidad sensible en el panorama de la vida cotidiana. Atenuada una en su condición virreinal por la insuficiencia política del Río de la Plata, rápidamente despojada la otra de la situación de sede imperial por obra de la modernización acelerada, Buenos Aires y Río son la contracara de las ansias monárquicas con que México y Lima reemplazaron el despojo sufrido por las ciudades indígenas. En el siglo XX en que la nota dominante es la figuración mundial y el olvido de los vínculos con la antigua metrópolis, todas ellas compiten 
por ocupar el lugar expectable de ciudad global, pero el ensayo, la crónica y la literatura les enrostran con su retórica soliviantada las fisuras históricas de semejante pretensión.

\section{Bibliografía}

Arguedas, José María. Los ríos profundos y cuentos selectos. Caracas: Biblioteca Ayacucho $\mathrm{n}^{\circ} 38,1982$.

Arlt, Roberto. Aguafuertes porteñas. Buenos Aires: Losada, 1981.

Bilac, Olavo. Estampas de Guanabara. Buenos Aires: Kraft, 1952.

Burgel, Guy. La revancha de las ciudades. Remedios de Escalada: Universidad Nacional de Lanús, 2014.

Celorio, Gonzalo. "Carlos Fuentes, epígono y precursor". En Carlos Fuentes. La región más transparente. Edición conmemorativa. Madrid: Real Academia Española, 2008.

El Matadero. Revista crítica de literatura argentina $\mathrm{n}^{\circ} 2$ 2. "La ciudad en la literatura argentina". Buenos Aires: Instituto de Literatura Argentina "Ricardo Rojas", Facultad de Filosofía y Letras - UBA, 2000.

Fuentes, Carlos. La región más transparente. Madrid: Real Academia Española, 2008.

Tiempo mexicano. México: Joaquín Mortiz, 1972.

Fustel de Coulanges, Numa Dionisio. La ciudad antigua. Buenos Aires: Albatros, 1942.

Gorelik, Adrián. Miradas sobre Buenos Aires. Historia cultural y crítica urbana. Buenos Aires: Siglo XXI, 2004.

Hardoy, Jorge y Richard P. Morse (comp.). Nuevas perspectivas en los estudios sobre historia urbana latinoamericana. Buenos Aires: Grupo Editor Latinoamericano, 1989.

Hardoy, Jorge y Richard P. Schaedel (comp.). Las ciudades de América Latina y sus áreas de influencia a través de la historia. Buenos Aires: Ediciones Siap, 1975.

Heffes, Gisela. Las ciudades imaginarias en la literatura latinoamericana. Rosario: Beatriz Viterbo, 2009.

Holanda, Sérgio Buarque de. Raízes do Brasil. São Paulo: Companhia das Letras, 2007. 
Lewis, Oscar. Los hijos de Sánchez. México: Joaquín Mortiz, 1965.

Mandel, Ernest. Crimen delicioso. Historia social del relato policíaco. Buenos Aires: Razón y Revolución, 2011.

Monsiváis, Carlos. Días de guardar. México: Era, 1969.

Mumford, Lewis. Textos escogidos. Ed. Daniel Mundo. Buenos Aires: Ediciones Godot, 2008.

Pacheco, José Emilio. "Carlos Fuentes en la región más transparente", en Carlos Fuentes. La región más transparente. Edición conmemorativa. Madrid: Real Academia Española, 2008 (XXIX-XXXVII).

Pirenne, Henri. La città del Medioevo. Bari: Laterza, 2011.

Poniatowska, Elena. La noche de Tlatelolco. México: Era, 1971.

Rama, Ángel. La ciudad letrada. Montevideo: Arca, 1989. Literatura, cultura, sociedad en América Latina. Selección e introducción de Pablo Rocca. Montevideo: Trilce, 2006.

Paz, Octavio. Posdata. México: Siglo XXI, 1987.

Reyes, Alfonso. Visión de Anáhuac (1915), en Obras Completas Volumen II. México: Fondo de Cultura Económica, 1986.

Rio, João do. A alma encantadora das ruas. São Paulo: Martin Claret, 2008.

Romero, José Luis. La ciudad occidental. Buenos Aires: Siglo XXI, 2009. Latinoamérica, las ciudades y las ideas. México: Siglo XXI, 1977.

Rotker, Susana. La invención de la crónica. Buenos Aires: Letra Buena, 1992.

Salazar Bondy, Sebastián. Lima la horrible. México: Era, 1977.

Sassen, Saskia. La ciudad global. Buenos Aires: Eudeba, 1999.

Scobie, James. Buenos Aires del centro a los barrios (1870-1910). Buenos Aires: Solar-Hachette, 1977.

Vargas Llosa, Mario. Conversación en La Catedral. Buenos Aires: AlfaguaraClarín, 2010 (a). La ciudad y los perros. Buenos Aires: Alfaguara-Clarín, 2010 (b). ."Sebastián Salazar Bondy y la vocación del escritor en Perú", en Contra viento y marea I (1962-1972). Barcelona: Seix Barral, 1990. Williams, Raymond. El campo y la ciudad. Buenos Aires: Paidós, 2001. 